\title{
Antimetastatic therapy at aberrant sialylation in cancer cells, a potential hotspot
}

\author{
Da-Yong Lu' ${ }^{1 *}$, Ting-Ren Lu ${ }^{2}$, Bin Xu ${ }^{3}$, Jian Ding ${ }^{3}$, En-Hong Chen ${ }^{3}$, Hong-Ying Wu ${ }^{2}$, Shu-Yun Wu $u^{3}$, Nagendra Sastry Yarla and Hong Zhu ${ }^{5}$ \\ ${ }^{1}$ School of Life Sciences, Shanghai University, PR China \\ ${ }^{2}$ College of Science, Shanghai University, PR China \\ ${ }^{3}$ Shanghai Institute of Material Medical, Chinese Academy of Sciences, PR China \\ ${ }^{4}$ GITAM University, AP, India \\ ${ }^{5}$ Zhejiang University, Zhejiang Sheng, PR China
}

\begin{abstract}
Neoplasm metastases involve a fixed cascade of pathological processes responsible for $90 \%$ cancer mortality worldwide. However, currently neoplasm metastases are poorly managed in humans for lack of good drug targets. To change this situation, new drug targets must be established. Aberrantly tumor sialylated study is one of potential drug targets, which has been involved for a half century. Many new discoveries show promising outcomes in experimental models. Since neoplasm tissues often contain higher levels of total sialic acids (sia), sialic acids-containing antigens, several types of sialic acid analogue, such as $\mathrm{N}$-glycolylneuraminic acids, growing attentions of sia-related tumor diagnostics and therapeutics are needed to work with new cancer treatment approaches. Previously some compounds that inhibit pathologic pathways of sialic acids in tumor movements in vitro and tumor metastasis in animal tumor models were found. This type of pharmacological limitations of cancer metastasis treatments can be possibly solved by future glycome/metabolomics technology utilities. As the "central dogma" of glycobiology is still unknown to us, some fundamental questions related to carbohydrate itself are even more important comparing with individual experimental discoveries. In addition, mathematicor physics-majored talents in this topic might catalyze these new discoveries. In this review, we document these strings of lab biologic evidence, drug development updating and close relationships between cancer pathological profiles and therapeutic targets/benefits in clinics.
\end{abstract}

\section{Topic generations}

Cancer is the second human mortality disease in the world. Unlike cardiovascular diseases, the treatment response for epithelial carcinoma has been hardly improved over the past several decades [1-3]. Neoplasm metastasis is one of the leading causalities for these therapeutic failure and $90 \%$ of cancer deaths. Paradoxically to our efforts and expectations, no obvious improvements and therapeutic benefits by mainstay of antimetastatic chemotherapeutic drugs [4-7]. Therapeutic benefits in late-staged or aged cancer patients are especially poor and useless [1-7]. Clinical anticancer drug therapies currently in use have been mainly focusing on primary tumor growth rather than specifically targeting long pathologic courses of metastases and remote organ neoplasm seeding [6,7]. Finding important drugs targets specifically to neoplasm metastases is essential and indispensable. It nevertheless needs changing our focus from targeting of vasculature and MMPs into other specific metastatic-relating molecules.

According to general points of view, good antimetastatic therapy must be based on thorough understanding of metastatic biology and pathology. Patho-physiology stages, genetic heterogeneous and organ preferences of cancers can be widely varied according to their differences in tumorigenic and metastatic evolutionary processes [5-8]. Before 2010, antimetastatic drugs extensively studied were focusing on antiangiogenesis agents and metalloproteinase inhibitors [6,7]. These two types of agents are only a few months of survival benefits generally and therapeutic variability among different cancer patients. In order to make marked breakthrough from this stalemate, novel ideas and some even shotgun-like molecular expeditions of drug developments seem to be a future solution [4-8]. Experimental and clinical antimetastatic approaches based on pathologic revelation and novel biomarker diagnostics have been originated since 2000 [4-8]. Among these efforts, some original and innovative approaches leading to final neoplasm metastasis managements are even more important and welcoming. One of these novel targets has been aberrant sialylation in neoplasm tissues [9-13]. It is not a well-defined therapeutic target that is waiting for stronger financial support. In this review, an important knowledge towards sialylation alterations in neoplasm tissues and drug targeting has been documented, discussed and highlighted for more ranges of audiences.

\section{Historic review and biomedical information gains in this topic}

Sialic acids (Sias, neuraminic acid) are a special series of 9-carbon backbone negatively charged carbohydrates and typically found at terminal sugar chains attached to cell glycoconjugates. They play critical roles in many physiological and pathologic processes, including inter-molecular binding that leads to microbial infections, regulation of the immune response, the progression/spread of human malignancies

Correspondence to: Da-Yong Lu, School of Life Sciences, Shanghai University, Shanghai 200444, PRC, Tel: +86 21 66163545; Fax: +821 66132177; E-mail: ludayong@shu.edu.cn

Key words: sialic acid, neuraminidic acids, neoplasm metastases, anticancer therapy, neoplasm targeting, probimane, sialylation, glycosylation, metabolomics, cancer chemotherapy, cancer biology, glycobiology

Received: January 09, 2017; Accepted: March 03, 2017; Published: March 06, 2017 
and in certain aspects of human evolution [14-16]. The earliest work tackling the close relationships between sias and tumors was traced back to Kimura et al from 1958 [17-18]. They discover that tumor cells might excrete and contain higher level of sias-containing glycoproteins. These characteristic later have been linked to highly metastatic tumor types $[19,20]$. Since then, numerous literatures showed similar data and lab findings [9-11]. Major milestone of this research can be mainly represented as follows (Figure 1).

\section{Current knowledges towards sia-related biologic and pathogenesis in cancer}

\section{Different sialic-acid contents and profiles in early cancer diagnostics}

More than 60 different forms of sias mono-sugar have ever been discovered [14], which can be linked with other normal mono sugars (heptose or hexose and so on) to form tremendously diversified 2-5 sugar component antigens (sugar chains) - sias are often at the farthest end of antigens and glycoproteins. Among these antigens, some of them are very tumorigenic and widely occurred among different tumors, such as sialyl Lewis $\mathrm{X}$ and $\mathrm{A}$ is known to correlate positively with colon and non small cell lung cancer and core a6-fucosylation with liver and pancreatic cancer [14-16]. These diversified antigenic features of cancers have been mainstreams of current biomedical efforts. It is enormously significant for cancer etiology, pathology, diagnostics and therapeutics [9-11]. Similarly, some sia-containing antigens show an important medical significance [21]. In order not to duplicate similar studies, we neglect large literature details.

\section{Human sialyltransferases and sialidase as cancer markers}

To consider the possible routes for tumor cells to accumulations of sias, one might immediately relate them with correspondent enzymes. Human sialyltransferases and sialidase as cancer marker and drug' targets have also been suggested along with sias containing antigens formation and aberrations. All the associations between linkage/ substitutions of sias and tumor malignancy progressions might be the causalities of gradually sialyltransferases or sialidases activity in tumors on the field of sia-related studies. It adds the volume of complexity and costs of sia-related study. Future new technologies will help us
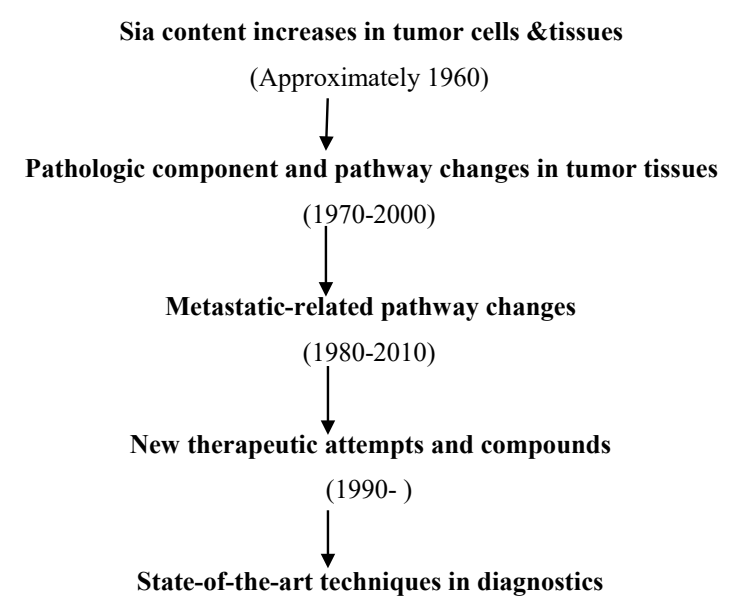

(2000-)

Figure 1. Panorama on relationship between sialic acid changes and modern medicine developments to understand these relationships between sia-biology and cancer diagnostics. Now, many sialyltransferases or sialidases have been found to express relatively higher or lower in tumors comparing with normal tissues [22-24]. This could be used as many important areas of cancer treatments, such as basic oncology studies, specific diagnostic value and therapeutic targets/responses to neoplasm metastasis.

\section{Diagnostic investigation and clinical applications}

There was once an argument that $\mathrm{N}$-glycolylneuraminic acid (Neu5Gc) is cancer-specific carbohydrate in humans [14-16]. This argument remains to be perfected because there is NeuGc in many other animals and species. Thus, we need to add a line of more diagnostic evidence and valuable theory to it. However, in our previous work, there is different levels and ratio of Neu5Ac, Neu5,9Ac and NeuGc in different tumor types and variable biological activities in tumor cells and tissues [25].

Apart for sia-analogue diagnostics, large bioinformatics data of both experiments and clinics are growing impacts on cancer diagnostics and treatments. We will show these techniques and pathogenesis elements in the following paragraphs.

We have previously discovered that NeuGc has higher biological activities than naturally most abundant sias analogue 5-acetylneuraminic acid (Neu5Ac, NANA) at equal molar concentrations. Some other researchers also reported changed activity between De$\mathrm{N}$-acetylneuraminic acid containing gangioside concentrations than acetylneuraminic acid containing gangiosides concentrations in cancers [26-28]. So this problem is an interesting, important and tough future challenge. It provides useful information of diversity property of sias in nature.

Owing to great duplicate of these literatures, this review cannot give full reference detail for most pathogenic and therapeutic studies before 2010. If readers are interested in full references, you can refer to our early literature review (Table 1) [9-11].

Since now there are many reports that hypoxia might lead to tumor out-side low $\mathrm{pH}[29,30]$. We think this might also be linked with higher sias levels. Because sias are negative charged sugars that ought to manifest low $\mathrm{pH}$ condition outside tumor cells.

\section{Bioinformatics and metabolomics}

Due to multiple reasons, we must pay more attentions to the regulation and functions of sias in cell, especially in cancer cells for diagnostic/therapeutic purposes. More realistic diagnostic models must be established. These researches have also been undergone. The commonest and sophisticate way to the study on the regulations of sias was glycome in the past [31-33]. Glycomes of sialylations mainly consist of lectin- or selectin-binding techniques or modern chromatography combined with mass-spectrometry. They demanded modern technology and instruments for glycome study comparing with colorimetry techniques for total sias contents and HPLC and/or GC method combined with fluorescence and/or electro-conductive detectors for sias analogues (Figure 2) [25]. Since more than 60 types of sias have been discovered until now, they are evolutionary and oncology related. Future new technologies will help us to understand these relations in quicker and easier ways. In addition, new technologies, especially in related with glycome and proteomics, immuno-histological tools and HPLC-MS can provide detailed biomedical information about small changes of sias in tumors. It might give birth to new round of remarkable and innovative therapeutic 


\section{Blood or urines}

(Sialic acid contents or profile, HPLC)

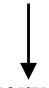

Tumor biopsy or surgery tissues (Invasive diagnostics)

(Glycomes or other bioinformatics)

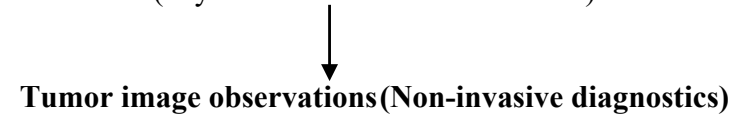

(PET or other new technologies)

Figure 2. Method evolutions of sialic acid pathologic/therapeutic studies in experiments

1. Early discoveries of relationships between neoplasm progresses and sialic acid aberration

\begin{tabular}{|c|c|c|}
\hline Types & Analogues or conjugates & Pathologic pathways \\
\hline Biology & \begin{tabular}{|l|l} 
Different sia analogues & \\
Glycoproteins \\
Glycolipids \\
Gangliosides \\
Glycan \\
Antigens (sialyl Lewis X) \\
Sialytransferases \\
Sialidase
\end{tabular} & $\begin{array}{l}\text { Chemical structural diversity ( }>60 \text { now) } \\
\text { Biological molecular processes and signal } \\
\text { pathways } \\
\text { Cell regulation and diversity } \\
\text { Cancer related pathways } \\
\text { Cancer or metastatic related pathways } \\
\text { Diagnostic or therapeutic importance } \\
\text { Glyco-synthesis processes } \\
\text { Glyco-decompose }\end{array}$ \\
\hline Pathology & $\begin{array}{l}\text { NeuGc } \\
\text { Sialytransferase activity } \\
\text { Different conjugates }\end{array}$ & $\begin{array}{l}\text { Commonly in human tissues } \\
\text { Malignancy ongoing } \\
\text { Different pathologic pathways }\end{array}$ \\
\hline Diagnostics & $\begin{array}{l}\text { Glyco-conjugate rise } \\
\text { Different sia profiles } \\
\text { Glycome } \\
\text { Image techniques (PET) } \\
\text { Detail bioinformatics }\end{array}$ & $\begin{array}{l}\text { Poor pregnancy \& tumor origin/types } \\
\text { Cancer biomarkers } \\
\text { Tumor pathogenic origin and types } \\
\text { Diagnostic or therapeutic values } \\
\text { Detail diagnostic information } \\
\text { Prognostic predictions }\end{array}$ \\
\hline Therapeutics & \begin{tabular}{|l|} 
Glyco- or antigen rise \\
Cell-surface glycan \\
change \\
Detail bioinformatics \\
Sialyl-antigen-derivatives \\
Sialyl-transferase \\
inhibitors
\end{tabular} & $\begin{array}{l}\text { Antibody or lectin treatments } \\
\text { Target anticancer drug developments } \\
\text { Signal pathways } \\
\text { Personalized cancer therapies } \\
\text { Tumor inhibitions via physiological } \\
\text { competitions } \\
\text { Tumor inhibitions via blockage of key } \\
\text { processes }\end{array}$ \\
\hline
\end{tabular}

study with sias-related pathways and tumor metastasis pathogenesis. Apart from that, some other technology and genetic means currently negligible, such as epigenetic considerations of sialylations in tumors might also be some important topics in future.

Imaging technology such as positron emission tomography (PET) $[34,35]$ is playing critical roles in biomedical studies. Imaging techniques are commonly non-invasive diagnostic tools. According to the technical feasibilities, sialic acid metabolism can also be monitored by PET by using different radioisotope labeled sia- substrate. Though it is difficult in human diagnostic studies, it can be widely used in animal studies by adding higher doses and longer intervals of radio tracers with no harm to human bodies. This great technical advance will accelerate sialic acids biomedical studies (Figure 2).

By PET utilities, we can evaluate tumor sia-related metabolisms for a long term in a lot of animals.

\section{Experimental therapeutic study}

It has a long history for therapeutic study of tumor growth and remote metastasis [9-11]. It involved from bioassays to anti-proliferative evaluation to anti-metastatic responses in murine tumor models
(Lewis lung carcinoma and melanoma B16). The therapeutic studies of sias-related Antimetastatic drugs began at approximately 30 years ago [12,25,36-46]. Since this type of anticancer drugs (especially targeting sias in tumors) has been seldom entering into clinical investigations, most experimental therapeutic studies have been collected here. We conclude as follows:

In the initial stages of therapeutic study, the antagonists had often been sias derivatives, conjugates and sias in macromolecules [36-40]. For example a sias-conjugator has been reported to inhibit pulmonary metastases of a mouse colon adenocarcinoma [36,37]. These data have been made in vitro or in mice tumor models. Only preclinical human toxicity data showed some hepatic toxicity of these agents after longterm tolerance evaluations [39]. A disaccharide precursor of sialyl Lewis X inhibits metastatic potential of tumor cells [40].

To evaluate a possibility of sias in tumors as a target against neoplasm metastasis, we have carried out a large-scale pharmacologic evaluation in mice for building the relation between sias inhibition and therapeutic response promotions of tested compounds and drugs (>10 anticancer drugs). The experimentation was to study if anticancer (especially Antimetastatic activity) drugs can substantially inhibit sias levels in mice bearing tumors [25,41]. Other similar reports have also shown these characters by plant extracts in mice bearing high metastatic tumors B16-F10 (Table 4) [42,43].

However, some licensed anticancer drugs such as 5-Fu that do not show typical Antimetastatic effects are also unable to inhibit sialic acid levels in tumor cells [44].

Chiang et al reported a novel sialyltransferase inhibitor AL10 can decrease adhesion, migration, actin-polymerization and invasions of tumor cells in vitro, however have no antiproliferative efficacy in cancer cells [45]. Moreover, sias-anticancer prodrug may increase its uptake and cytotoxicity against tumor cells (Figure 3 and Table 3) [46].

\section{Future directions}

Biomedical studies of sialic acid are growing importance now $[47,48]$. We have offered a quick glimpse of the critical components or pathways of relationships between cancer progresses and sialylation

Table 2. The influence of Sulforaphane on serum sialic acid level in mice bearing B16F-10

\begin{tabular}{|c|c|c|}
\hline & Schedule & Sialic acid $\mu \mathrm{g} / \mathrm{ml}$ \\
\hline Control (normal mice) & No tumor inoculation & $21.3 \pm 1.5$ \\
\hline Tumor-bearing mice & Melanoma inoculation & $108.26 \pm 1.92$ \\
\hline Sulforaphane & Simultaneously (drug) & $35.13 \pm 0.9$ \\
\hline Sulforaphane & Prophylactic & $59.51 \pm 1.2$ \\
\hline Sulforaphane & Developed metastases & $92.88 \pm 1.23$ \\
\hline
\end{tabular}

\section{Blood or urines}

(Sialic acid contents or profile, HPLC)<smiles>[Te]</smiles>

Tumor biopsy or surgery tissues (Invasive diagnostics)

(Glycomes or other bioinformatics)

Tumor image observations(Non-invasive diagnostics)

(PET or other new technologies)

Figure 3. General routines in future clinical diagnostics 
Table 3. Different modes of anticancer agents or drugs in sia-related targets and pathways

\begin{tabular}{|l|l|l|}
\hline Therapeutic types & Target or models & Reference \\
\hline Sia-analog \& derivatives & $\begin{array}{l}\text { Bioassay } \\
\text { Tumor inhibitions in vitro } \\
\text { Metastasis inhibitions in } \\
\text { animal tumor models }\end{array}$ & $12,36-37,40$ \\
\hline Compounds & $\begin{array}{l}\text { Serum sialic acid level in } \\
\text { mice bearing tumor }\end{array}$ & $25,41-43$ \\
\hline New compounds & Phase I clinical evaluations & 39 \\
\hline Novel compounds & $\begin{array}{l}\text { Biochemical assay } \\
\text { (Sialyltransferase } \\
\text { inhibitions) }\end{array}$ & 45 \\
\hline Pro-drugs & Tumor affinity & 46 \\
\hline
\end{tabular}

Table 4. Future directions of sialic acid-related pathologic and therapeutic studies

\begin{tabular}{|l|l|}
\hline Categories & Methodology \\
\hline Experimental screen in vitro & Tumor cell screening \\
Genetic-modified tumor cells \\
Drug develop study \\
Tumor genomic study (NGS)
\end{tabular}

aberrant in tumor tissues in this article. Though many statements are given, a lot of questions remain to be answered. We conclude four major parts

1) The exact regulation pathways lead to changes of sialylation in tumors, and can we precisely control them in future?

2) Diagnostic technique updating to its reasonable price and may lead to early diagnosis of cancer or metastasis for different types of personalized cancer chemotherapy [49-51].

3) More intensively mathematic analysis of experimental and clinical data [52-54]. Across the history, many unexpected biomedical discoveries were coming from the cooperative studies between biomedical scientists and mathematic- and theoretic physicists [54].

4) Anything leading to therapeutic response improvements, especially from the angel of neoplasm metastases pathology and therapeutic interventions might be of a great biomedical significance.

We think these questions are important to be understood. The rules of sias in nature must have significant cancer therapeutic values (Table 4).

Sias largely presenting in nature may play diversity physiologic and pathologic roles among large populations of living bodies $[47,48]$. Therapeutic drugs targeting to different ranges of sia-related pathways might lead to new ways of neoplasm inhibitions. It can add expanding capabilities of drug arsenal and clinical paradigms. As the central dogma of glycobiology is not established [48] some fundamental questions related to carbohydrate itself $[10,11]$ are even more important than our understanding nature and diseases at this stage. A bright future is waiting for us if we insist on these types of biomedical researches.

\section{Conclusion}

There are plenty of questions to be asked and answered upon pathology/therapeutics relationship between sias and tumors. This needs times, fortunes and high-talented scientists. However, better understanding of tumor metastases and therapeutic-related mechanisms is quite necessary. In this critical time, we need to change our focus away from angiogenic therapy into new approaches such as aberrant sialylation in tumors.

\section{Conflict of interests}

\section{None}

\section{Acknowledgement}

This work was supported by Shanghai Science and Technology Foundation of High Education. 97A49

\section{References}

1. Varmus H (2006) The new era in cancer research. Science 312: 1162-1165. [Crossref]

2. Siegel RL, Miller KD, Jemal A (2016) Cancer Statistics. Cancer J Clin 66: 7-30 [Crossref]

3. Hahn WC (2004) Cancer: surviving on the edge. Cancer Cell 6: 215-222. [Crossref]

4. Talmadge JE, Fidler IJ (2010) AACR centennial series: the biology of cancer metastasis: historical perspective. Cancer Res 70: 5649-5669. [Crossref]

5. Valastyan S, Weinberg RA (2011) Tumor metastasis: molecular insights and evolving paradigms. Cell 147: 275-292. [Crossref]

6. Lu DY, Lu TR, Cao S (2012) Cancer metastases and clinical therapies. Cell \& Developmental Biology 1: e110

7. Lu DY, Lu TR, Wu HY, Cao S (2013) Cancer metastases treatments. Current Drug Therapy 8: 24-29.

8. Lu DY, Lu TR, Xu B, Qi RX, Sastry NY, et al. (2016) Cancer metastasis, a clinical dilemma for therapeutics. Current Drug Therapy 11: 163-169.

9. Lu D Y, Cao J Y (2001) Structural aberration of cellular sialic acids and their functions in cancer. J Shanghai Univ (Eng) 5: 164-170

10. Lu DY, Lu TR, Wu HY (2012) Development of antimetastatic drugs by targeting tumor sialic acids. Sci Pharm 80: 497-508. [Crossref]

11. Lu DY, Lu TR, Wu HY (2011) Antimetastatic therapy targeting aberrant sialylation profiles in cancer cells. Drug Therapy Studies 1: e12

12. Büll C, Boltje TJ, Wassink M, de Graaf AM, van Delft FL, et al. (2013) Targeting aberrant sialylation in cancer cells using a fluorinated sialic acid analog impairs adhesion, migration, and in vivo tumor growth. Mol Cancer Ther 12: 1935-1946. [Crossref]

13. Freire-de-Lima L, Previato JO and Mendonca-Previato L (2016) Glycosylation changes in cancer: An innovative frontier at the interface of cancer and glycol-biology. Frontiers in Oncology 2016; 6, 254 Doi:10.3389/fonc.2016.00254

14. Angata T, Varki A (2002) Chemical diversity in the sialic acids and related alpha-keto acids: an evolutionary perspective. Chem Rev 102: 439-469. [Crossref]

15. Faillard H (1989) The early history of sialic acids. Trends Biochem Sci 14: 237-241 [Crossref]

16. Varki NM, Varki A (2007) Diversity in cell surface sialic acid presentations implications for biology and disease. Lab Invest 87: 851-857. [Crossref]

17. Turumi K, Dawes ML (1958) Serum sialic acid levels in mice with neoplasms. Cancer Res 18: 575-577. [Crossref]

18. Kimura A, Nagai Y, Turumi K, Kawashima Y, Sato H (1961) Hexosamine and sialic acid contents in cells. Nature 191: 596. [Crossref]

19. Yogeeswaran G, Sebastian H, Stein BS (1979) Cell surface sialylation of glycoprotein and glycosphingolipids in cultured metastatic variant RNA-virus transformed nonproducer BALB/c 3T3 cell lines. Int J Cancer 24: 193-202. [Crossref]

20. Yogeeswaran G, Salk PL (1981) Metastatic potential is positively correlated with cell surface sialylation of cultured murine tumor cell lines. Science 212: 1514-1516 [Crossref] 
21. Yu LG (2007) The oncofetal Thomsen-Friedenreich carbohydrate antigen in cancer progression. Glycoconjugate J 24: 411-420 [Crossref]

22. Peracaula R, Tabares G, Lopez-Ferrer A, Brossmer R, de Bolos C, et al. (2005) Role of sialyltransferases involved in the biosynthesis of Lewis antigens in human pancreatic tumour cells. Glycoconjugate $J$ 22: 135-144 [Crossref]

23. Dall'Olio F, Chiricolo M (2001) Sialyltransferases in cancer. Glycoconj $J$ 18: 841-850. [Crossref]

24. Miyagi T, Wada T, Yamaguchi K, Shiozaki K, Sato I, et al. (2008) Human sialidase as a cancer marker. Proteomics 8: 3303-3311. [Crossref]

25. Lu DY, Liang G, Zhang MJ, Xu B (1994) Serum contents of sialic acids in mice bearing different tumors. Chin Sci Bull Eng 39: 1220-1223

26. Sjoberg ER, Chammas R, Ozawa H, Kawashima I, Khoo JK et al. (1995) Expression of De-N-acetyl-gangliosides in human melanoma cells is induced by genistein or nocodazole. J Biol Chem 270: 2921-2930 [Crossref]

27. Zhou QH, Hakomori SI, Kitamura K, Igarashi Y (1994) GM3 directly inhibits tyrosine phosphorylation and De-N-acetyl-GM3 directly enhances serine phosphorylation of epidermal growth factor receptor, independent of receptor interaction. $J$ Biol Chem 269: 1959-1965 [Crossref]

28. Hanai N, Dohi T, Nores GA, Hakomori S (1988) A novel gangioside, De-N-acetylGM3 (II3 NeuNH2LacCer), acting as a strong promoter for epidermal growth factor receptor kinase and as a stimulator for cell growth. J Biol Chem 263: 6296-6301.

29. Sonnenburg JL, van Halbeek H, Varki A (2002) Characterization of the acid stability of glycosidically linked neuraminic acid: use in detecting de-N-acetyl-gangliosides in human melanoma. J Biol Chem 277: 17502-17510. [Crossref]

30. Chiche J, Brahimi-Horn MC, Pouysségur J (2010) Tumour hypoxia induces a metabolic shift causing acidosis: a common feature in cancer. J Cell Mol Med 14: 771794. [Crossref]

31. Feizi T (2000) Progress in deciphering the information content of the 'glycome'--a crescendo in the closing years of the millennium. Glycoconj J 17: 553-565. [Crossref]

32. Naka R, Kamoda S, Ishizuka A, Kinoshita M, Kakehi K (2006) Analysis of total $\mathrm{N}$-Glycans in cell membrane fractions of cancer cells using a combination of serotonin affinity chromatography and normal phase chromatography. J Proteome Res 5: 88-97 [Crossref]

33. Lin SY, Chen YY, Fan YY, Lin CW, Chen ST, et al. (2008) Precise mapping of increased sialylation pattern and the expression of acute phase proteins accompanying murine tumor progression in $\mathrm{BALB} / \mathrm{c}$ mouse by integrated sera proteomics and glycomics. J Proteome Res 7: 3293-3303 [Crossref]

34. Challapalli A, Aboagye EO (2016) Positron emission tomography imaging of tumor cell metabolism and application to therapy response monitoring. Frontiers in Oncology 2016; 6, 44. Doi:10.3389/fonc.2016.00044 [Crossref]

35. Serkova NJ, Eckhardt SG (2016) Metabolic Imaging to Assess Treatment Response to Cytotoxic and Cytostatic Agents. Front Oncol 6: 152. [Crossref]

36. Kijima-Suda I, Miyamoto Y, Toyoshima S, Itoh M, Osawa T (1986) Inhibition of experimental pulmonary metastasis of mouse colon adenocarcinoma 26 sublines by a sialic acid: nucleoside conjugate having sialyltransferase inhibiting activity. Cancer Res 46: 858-862 [Crossref]
37. Kijima-Suda I, Miyazawa T, Itoh M, Toyoshima S, Osawa T (1988) Possible mechanism of inhibition of experimental pulmonary metastasis of mouse colon adenocarcinoma 26 sublines by a sialic acid: nucleoside conjugate. Cancer Res 48: 3728-3732 [Crossref]

38. Radin NS, Inokuchi J (1988) Glucosphingolipids as sites of action in the chemotherapy of cancer. Biochem Pharmacol 37: 2879-2886. [Crossref]

39. Goss PE, Baptiste J, Fernandes B, Baker M, Dennis JW (1994) A phase I study of swainsonine in patients with advanced malignancies. Cancer Res 54: 1450-1457. [Crossref]

40. Fuster MM, Brown JR, Wang LC, Esko JD (2003) A disaccharide precursor of sialyl Lewis X inhibits metastatic potential of tumor cells. Cancer Res 63: 2775-2781. [Crossref]

41. Lu DY, Xu J, Lu TR, Wu HY, Xu B (2013) Inhibitions of several antineoplastic drugs on serum sialic Acid levels in mice bearing tumors. Sci Pharm 81: 223-231. [Crossref]

42. Thejass P, Kuttan G (2006) Antimetastatic activity of Sulforaphane. Life Sci 78: 30433050. [Crossref]

43. Lee SJ, Chung IM, Kim MY, Park KD, Park WH, et al. (2009) Inhibition of lung metastasis in mice by oligonol. Phytother Res 23: 1043-1046. [Crossref]

44. Abde-Hamid NM, Morsy MA (2010) Novel biochemical pathways for 5-fluororacil in managing experimental hepatocellular carcinoma in rats. J Membrane Biol 234: 29-34. [Crossref]

45. Chiang $\mathrm{CH}$, Wang $\mathrm{CH}$, Chang HC, More SV, Li WS, et al. (2010) A novel sialyltransferase inhibitor AL10 suppresses invasion and metastasis of lung cancer cells by inhibiting integrin-mediated signal. J Cell Physiol 223: 492-499. [Crossref]

46. Jayant S, Khandare JJ, Wang Y, Singh AP, Vorsa N, et al. (2007) Targeted sialic aciddoxorubicin prodrugs for intracellular delivery and cancer treatment. Pharm Res 24 2120-2130. [Crossref]

47. Varki A (2008) Sialic acids in human health and disease. Trends Mol Med 14: 351-360. [Crossref]

48. Nagai Y (2002) Glycobiology in the 21st century: coming developments in glycobiology. Glycoconj J 19: 161-163. [Crossref]

49. Lu DY, Lu TR, Wu HY (2014) Personalized cancer therapy, a perspective. Clinical Experimental Pharmacology 4: 153

50. Lu DY (2014) Personalized cancer chemotherapy, an effective way for enhancing outcomes in clinics. Metabolomics 4: e99

51. Span PN (2015) From eels to the importance of cancer bio banks. Future Sci OA 1 FSO65. [Crossref]

52. Woods RJ (1998) Computational carbohydrate chemistry: what theoretical methods can tell us? Glycoconj J 15: 209-216. [Crossref]

53. Lu DY, Lu TR (2015) Mathematics or physics-majored students on the biomedical fields, insiders or outsiders? Metabolomics 5: e142

54. Lu DY, Wu HY, Lu TR, Che JY, Lu Y (2016) Updating biomedical studies by recruiting more mathematics or physics-majored talents. Metabolomics 6: e148

Copyright: (C2017 Lu DY. This is an open-access article distributed under the terms of the Creative Commons Attribution License, which permits unrestricted use, distribution, and reproduction in any medium, provided the original author and source are credited. 